\title{
PREVALENCE OF FAILURE OF FIRST-LINE ANTIRETROVIRAL THERAPY- STUDY AT RIMS, A TERTIARY CARE HOSPITAL AT ONGOLE, PRAKASAM DISTRICT OF ANDHRA PRADESH
}

\author{
Gudi Srinivas ${ }^{1}$, Yarram Rajeswara Rao², Jyothula Joseph Samuel ${ }^{3}$
}

${ }_{1}^{1}$ Associate Professor, Department of General Medicine, Rajiv Gandhi Institute of Medical Sciences, Ongole, Andhra Pradesh, India. ${ }^{2}$ Assistant Professor, Department of General Medicine, Rajiv Gandhi Institute of Medical Sciences, Ongole, Andhra Pradesh, India. ${ }^{3}$ Senior Medical Officer, ART Centre, Rajiv Gandhi Institute of Medical Sciences, Ongole, Andhra Pradesh, India.

\section{ABSTRACT}

\section{BACKGROUND}

HIV infection is not the end of life. Anti-retroviral therapy (ART) effectively suppresses replication. But adherence to ART regimen is therefore very vital. Any irregularity in following the prescribed regimen can lead to resistance to HIV drugs and therefore can weaken or negate its effect.

\section{MATERIALS AND METHODS}

A retrospective descriptive study was done from the ART centre at Rajiv Gandhi Institute of Medical Sciences (RIMS), Ongole. Data from case sheets was collected in a pre-designed format. This study was conducted from 2007 to 2017 . Treatment failure is identified by clinical and/ or immunological and confirmed by the virological criteria.

\section{RESULTS}

Among the total of 8119 patients, total first-line failures who were on second-line drugs were 254; hence, the prevalence of failure of first-line anti-retroviral therapy being $3.12 \%$. Out of the total first-line failures, $133(52.4 \%)$ were males and 121 (47.6\%) were females. The mean age of the first-line failures was $37.52 \pm 10.41$ years. Mean baseline CD4 count was $195.42 \pm 81.56 \mathrm{~mm}^{3}$.

\section{CONCLUSION}

The overall prevalence of first-line anti-retroviral therapy was found to be $3.12 \%$ with a slight male preponderance and majority belonged to relatively younger age group. Constant monitoring and individual counselling on all aspects of the treatment would play an important role.

\section{KEY WORDS}

HIV/ AIDS, First-Line ART, Failure, Prevalence.

HOW TO CITE THIS ARTICLE: Srinivas G, Rao YR, Samuel JJ. Prevalence of failure of first-line antiretroviral therapy- study at RIMS, a tertiary care hospital at Ongole, Prakasam district of Andhra Pradesh. J. Evolution Med. Dent. Sci. 2018;7(22):2690-2693, DOI: $10.14260 /$ jemds/2018/606

\section{BACKGROUND}

Recognised in 1980's, HIV/ AIDS has rapidly established itself throughout the world and is likely to endure and persist well into the $21^{\text {st }}$ century affecting tens of millions people.

According to Global recent estimates by World Health Organisation (WHO), there were approximately 36.7 million people living with HIV (PLHIV) at the end of 2016 with 1.8 million people becoming newly infected in 2016 globally. $54 \%$ of adults and $43 \%$ of children living with HIV are currently receiving lifelong antiretroviral therapy (ART) and estimated 20.9 million people living with HIV were receiving ART by mid-2017.[1]

At National level according to estimates for the year 2016, 2.1 million people were living with HIV in India with estimated 80,000 new HIV infections. HIV prevalence in adults was $0.3 \%$. During 2015 of the 2.1 million estimated cases, 1.4 million (67\%) were diagnosed as having HIV and of these 7, 47 and 175 (50\%) were on ART. [2,3]

'Financial or Other Competing Interest': None.

Submission 05-05-2018, Peer Review 16-05-2018,

Acceptance 19-05-2018, Published 28-05-2018.

Corresponding Author:

Dr. Yarram Rajeswara Rao,

House No. 37-1-383 (112),

Indira Colony, Opp. Dr. Ambedkar Bhavan,

Ongole Prakasam-523001, Andhra Pradesh.

E-mail: yarram.rajeswararao@gmail.com

DOI: $10.14260 /$ jemds $/ 2018 / 606$

\section{(c) (i) $\$$}

HIV infection is not the end of life. People can lead a healthy life for a long time with appropriate medical care. Anti-retroviral therapy (ART) effectively suppresses replication, if taken at the right time. Successful viral suppression restores the immune system and halts onset and progression of disease as well as reduces chances of getting opportunistic infections. Medication thus enhances both quality of life and longevity. But adherence to ART regimen is therefore very vital in this treatment. Any irregularity in following the prescribed regimen can lead to resistance to HIV drugs and therefore can weaken or negate its effect.[4,5]

Limited studies have been documented on the failures of first-line anti-retroviral therapy and hence the present study has been designed with an objective to determine the prevalence of failure of first-line anti-retroviral therapy in the study area.

\section{MATERIALS AND METHODS}

A retrospective descriptive study was done from the ART centre at Rajiv Gandhi Institute of Medical Sciences (RIMS), Ongole. This centre follows guidelines of National AIDS Control Organisation (NACO) for treatment of HIV patients. Data from case sheets was collected in a pre-designed format. This study was conducted from 2007 to 2017.

Data abstraction format contained patient demographics, baseline characteristics, treatment related data and treatment failure related information. Inclusion criteria were patients aged more than 15 years of age and on anti- 
retroviral therapy for at least six months and above. Patients who were on alternative first-line therapy, lost for follow-up, infected with HIV 2 and expired were excluded from the study.

According to the NACO guidelines, first-line ART is the initial regimen prescribed for an ART naive patient when the patient fulfils national, clinical and laboratory criteria to be initiated on ART. (Current NACO treatment guidelines for first-line ART recommend three drug combination therapy from 2 classes of ARV drugs for initial treatment, i.e. 2 NRTI + 1 NNRTI).[6]

Second-line ART is the subsequent regimen used in sequence immediately after first-line therapy has failed. (Current NACO treatment guidelines recommend use of Ritonavir-boosted protease inhibitors (bPIs) supported by two agents from the NRTI class, of which at least one should be new.

Treatment failure refers to the loss of antiviral efficacy to current regimen and it triggers the SWITCH of the entire regimen from First-to-Second line.[6]

It is Identified by Clinical and/ or Immunological and Confirmed by the Virological Criteria-

a. Clinical Failure: New or recurrent WHO stage 4 condition, after at least 6 months on ART.

b. Immunological Failure: Fall of CD4 count to pretherapy baseline (or below), $50 \%$ fall from the ontreatment peak value, persistent CD4 levels below 100 cells/mm3.

c. Virological Failure: Plasma viral load $>1,000$ copies/mL.

\section{Statistical Analysis}

Collected data from white cards was entered into Microsoft Excel 2010 version. Data was presented in percentages and proportions. Bar diagrams and pie charts were used to represent the data.

\section{RESULTS}

A total of about 21,000 people living with HIV (PLHIV) were registered at the ART centre in the study period, of which 8119 patients are alive on first-line anti-retroviral drugs. Out of whom 3557 were males and 4562 females, rest of the people were dropouts due to various reasons. Some expired and some were transferred to other centres.

One of the core objectives of the present study was to determine the overall prevalence of failure of first-line antiretroviral therapy. Among the total 8119 patients, total firstline failures who were on second-line drugs were 254; hence, the prevalence of failure of first-line anti-retroviral therapy being $3.12 \%$. Non-failures of ART in the present study were 7 , 865 patients with a percentage of $96.88 \%$. This indicates that first-line ART is effective in the treatment provided taken regularly and maintaining adherence.

Out of the total first-line failures, 133 (52.4\%) were males and $121(47.6 \%)$ were females.

The mean age of the first-line failures was $37.52 \pm 10.41$ years. Mean age among males was $37.5 \pm 10.4$ years and among females was $36.5 \pm 9.7$ years.

Among the first-line failures, the mean duration of antiretroviral therapy in months was $82.34 \pm 11.5$ months.

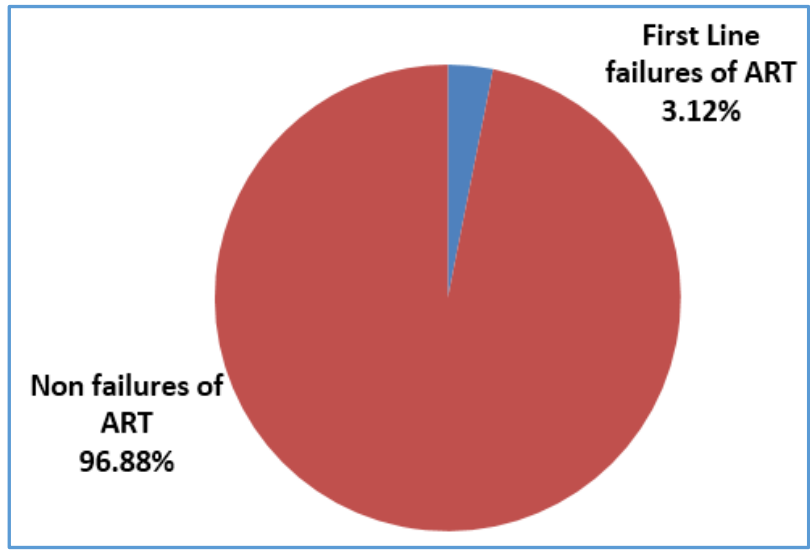

Graph 1. First-Line Failures of Anti-Retroviral Therapy

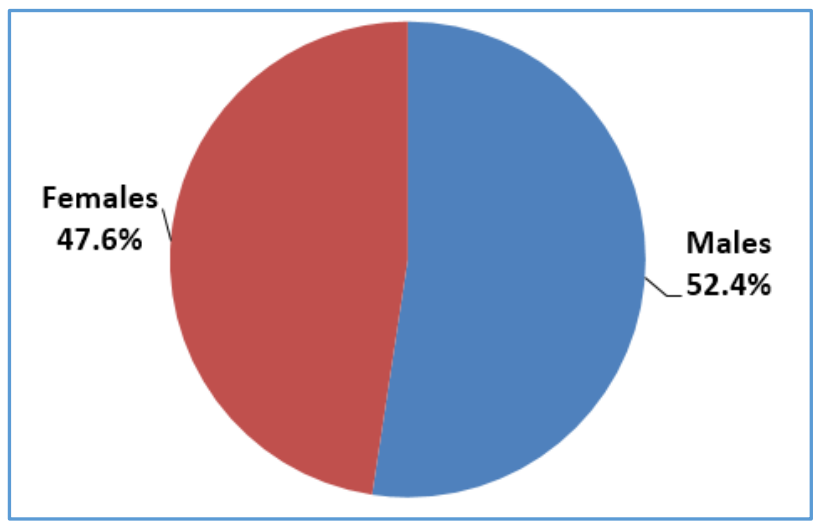

Graph 2. Gender-Wise distribution of FirstLine Failures of ART

With regards to baseline CD4 count of 254 patients, majority (38.2\%) of patient's CD count was in the $101-200$ range followed by $>200$ group (33.1\%). Mean baseline CD4 count was $195.42 \pm 81.56$ cells $/ \mathrm{mm}^{3}$.

CD4 counts were regularly monitored and the recent CD4 count showed the following findings: Mean recent CD4 count was found to be $156.61 \pm 147.30 \mathrm{cells} / \mathrm{mm}^{3}$. One-thirds (36.3\%) were in the range of $101-200$ CD 4 cells followed by $22 \%$ in $<50$ and $>200$ cells range group.

\begin{tabular}{|c|c|}
\hline Baseline CD4 Count (cells $/ \mathrm{mm}^{3}$ ) & No. (\%) \\
\hline$<50$ & $31(12.2 \%)$ \\
\hline $50-100$ & $42(16.5 \%)$ \\
\hline $101-200$ & $97(38.2 \%)$ \\
\hline$>200$ & $84(33.1 \%)$ \\
\hline
\end{tabular}

Table 1. Baseline CD4 Count among First-Line Treatment Failures of $A R T$

Mean baseline CD4 count $=195.42 \pm 81.56$

Viral load assessment was done at the time of State AIDS Clinical Expert Panel (SACEP) assessment (baseline). Mean viral load was found to be $203713.21 \pm 749687.1$.

Initiation of second-line ART regimen among first-line failures of ART:

With regards to type of second-line Anti-Retroviral Therapy, which was initiated among first-line failures found that majority $(88.2 \%)$ were started on the Tenofovir $300 \mathrm{mg}$ + Tab. Atazanavir $300 \mathrm{mg}$, Tab. Ritonavir $100 \mathrm{mg}$ each tab to be taken once daily simultaneously $(\mathrm{TL}+\mathrm{ATV} / \mathrm{r})$. 
$\mathrm{ZL}+\mathrm{ATV} / \mathrm{r}$ combination of Zidovudine + Lamivudine and Atazanavir $300 \mathrm{mg}$, Tab. Ritonavir $100 \mathrm{mg}$ was given in $6.3 \%$ $(\mathrm{n}=16)$ and $5.5 \%(\mathrm{n}=14)$ were kept on Atazanavir/ Ritonavir $(\mathrm{ATV} / \mathrm{r})+$ Abacavir/Lamivudine (ABC/3TC) combination.

\begin{tabular}{|c|c|}
\hline ART Regimen & No. (\%) \\
\hline $\mathrm{TDF} / \mathrm{TL}+\mathrm{ATV} / \mathrm{r}$ & $224(88.2 \%)$ \\
\hline $\mathrm{ABC}+3 \mathrm{TC}+\mathrm{ATV} / \mathrm{r}$ & $14(5.5 \%)$ \\
\hline $\mathrm{ZL}+\mathrm{ATV} / \mathrm{r}$ & $16(6.3 \%)$ \\
\hline Table 2. Second-Line ART Regimen initiated \\
among First-Line Failures of ART
\end{tabular}

\section{DISCUSSION}

The identification and management of first-line ART failure is a key challenge for reducing burden of HIV in resource limited countries like India and also financial constraints have to be taken into consideration.

The present study has been done to determine the prevalence of failure of first-line anti-retroviral therapy in ART centre at Rajiv Gandhi Institute of Medical Sciences (RIMS), which is a tertiary level hospital in Ongole, Prakasam district of Andhra Pradesh.

\section{Prevalence of Failure of First-Line Anti-Retroviral Therapy}

In the present study, the overall prevalence of failure of firstline anti-retroviral therapy was found to be $3.12 \%$.

In concurrence to the present study, similar kind of study done by Biset Ayalew et al (2016) ${ }^{[7]}$ in Northwest Ethiopia found a total of $4.1 \%$ patients who were found to have treatment failure.

But in contrast to the study findings, study by Seshaiah $\mathrm{KV}$ et al (2015)[8] in six districts of Andhra Pradesh documented a prevalence of first time ART to be only $0.47 \%$, indicating the efficacy of first-line ART.

A higher prevalence of first-line ART failure was noted in a study from South India by Kumarasamy N et al (2006)[9]; wherein $14 \%$ patients experienced treatment failure.

Other studies in various geographical areas found varied prevalence. Study by Dragsted et al (2004) ${ }^{[10]}$ reported that the incidence of treatment failure at 12 months was 11.6 per 100 person-years of follow-up and that reduced over time. Study by HM Jaka et al (2009)[11] observed a prevalence of treatment failure to be $62 / 362(17.1 \%)$ with mean duration follow-up of 29 months.

\section{Among Failed patients, the Mean Durability of First Line}

Rajasekaran et al (2007)[12] reported in their study that cumulative incidence of treatment failure among 1370 patients was $3.9 \%$.

TREAT Asia HIV Observational Database (TAHOD) ${ }^{[13]}$ showed that the rate of clinical failure was 7.3 per 100 people-years.

With regards to gender distribution, there was a slight male preponderance observed in the present study with $52.4 \%$ failures compared with $47.6 \%$ females. Similar findings were found in Seshaiah KV et al (2015),[8] where a higher incidence of first-line ART failures among males were compared to females.
In contrast, Biset Ayalew et al (2016) ${ }^{[7]}$ observed that nearly three out of five $(60.3 \%)$ patients were females.

In the present study, age distribution found a relatively younger age group with a mean of 37.52 years among the first-line failures. Similar results were seen in Biset Ayalew et al (2016), ${ }^{[7]}$ where majority (50.9\%) belonged to $31-45$ years' age group and $41.2 \%$ in 18 - 30 years' age group.

The mean baseline CD4 count in the present study was $195.42 \pm 81.56$ cells $/ \mathrm{mm}^{3}$, which was similar to baseline mean CD4 cells of 212.7 cells $/ \mathrm{mm}^{3}$. In Biset Ayalew et al (2016) ${ }^{[7]}$ study and also in HM Jaka et al (2009),[11] where mean baseline $\mathrm{CD} 4$ count was 121 cells $/ \mu \mathrm{L}$.

\section{Limitations of the Study}

Since the study was retrospective, the accuracy of findings was completely dependent on data in the case records.

\section{CONCLUSION}

The overall prevalence of first-line anti-retroviral therapy was found to be $3.12 \%$ with a slight male preponderance and majority belonged to relatively younger age group. Good adherence to anti-retroviral therapy is the key for the prevention of drug resistance and proper cure of the patient. Constant monitoring and individual counselling on all aspects of the treatment would play an important role.

\section{REFERENCES}

[1] WHO (2018) Factsheets on HIV/AIDS http://www.who.int/en/news-room/factsheets/detail/hiv-aids (last accessed 21-04-18)

[2] Annual report 2016-17, NACO, Department of AIDS Control, Ministry of Health and Family Welfare, New Delhi, Govt. of India. 2015.

[3] WHO (2015), Country Fact Sheet, HIV/AIDS in India, Dec. 2015.

[4] National Strategic Plan for HIV/AIDS and STI 20172024. NACO, Department of AIDS control, Ministry of Health and Family Welfare, New Delhi, Govt. of India. 2017.

[5] WHO Revision on: Antiretroviral therapy for HIV infection in adults and adolescent, 2013.

[6] National Guidelines on Second-line ART and Alternative First-line ART for Adults and Adolescents. NACO, Department of AIDS Control, Ministry of Health and Family Welfare, New Delhi, Govt. of India. 2013.

[7] Ayalew MB, Kumilachew D, Belay A, et al. First-line antiretroviral treatment failure and associated factors in HIV patients at the University of Gondar Teaching Hospital, Gondar, Northwest Ethiopia. HIV/AIDS (Auckl) Research and Palliative Care 2016;8:141-6.

[8] Seshaiah KV, Rao SD, Rao SK, et al. Prevalence of failure of first-line anti-retroviral therapy in HIV patients: a retrospective cross-sectional study of six districts of Andhra Pradesh over one decade. Sch J App Med Sci 2015;3(2C):705-9.

[9] Kumarasamy N, Vallabhaneni S, Cecelia AJ, et al. Reasons for modification of generic highly active antiretroviral therapeutic regimens among patients in Southern India. J Acquir Immune Defic Syndr 2006;41(1):53-8. 
[10] Dragsted UB, Mocroft A, Vella S, et al. Predictors of immunological failure after initial response to highly active antiretroviral therapy in HIV-1 infected adults: a Euro SIDA study. J Infect Dis 2004;190(1):148-55.

[11] Jaka HM, Mshana SE, Liwa AC, et al. Prevalence of immunological failure and durability of first line antiretroviral therapy at Bugando Hospital Mwanza, Tanzania. Tanzania Medical Journal 2009;24(2):5-8.
[12] Rajasekaran S, Jeyaseelan L, Vijila S, et al. Predictors of failure of first-line antiretroviral therapy in HIVinfected adults: Indian experience. AIDS 2007;21(Suppl 4):S47-S53.

[13] Zhou J, Paton NI, Ditangco R, et al. Experience with the use of a first-line regimen of stavudine, lamivudine, and nevirapine in patients in the TREAT Asia HIV Observational Database. HIV Med 2007;8(1):8-16. 